\title{
The Timing of Endoscopic Evaluation of Anti-TNFa Therapy Patients with Ulcerative Colitis
}

Hiroyuki Kashiwagi ${ }^{*}$, Ayumi Ito, Harutaka Kambayashi, Shun Murasugi, Teppei Omori, Maria Yonezawa, Shinichi Nakamura, Katsutoshi Tokushige

Departoment of Gastroenterology, Tokyo Women's Medical University. 8-1 Kawada-cho, Shinjukuku, Tokyo 162-8666, Japan; E-Mails: k0215hiro@gmail.com; ito.ayumi@twmu.ac.jp; kambayashi.harutaka@twmu.ac.jp; murasugi.shun@twmu.ac.jp; omori.teppei@twmu.ac.jp; yonezawa.ige@twmu.ac.jp; shinichi.ige@twmu.ac.jp; tokushige.ige@twmu.ac.jp

* Correspondence: Hiroyuki Kashiwagi; E-Mail: k0215hiro@gmail.com

Academic Editor: Massimo Arcerito

Special Issue: Gastroesophageal Reflux Disease: From Heartburn to Esophageal Adenocarcinoma

OBM Hepatology and Gastroenterology

2021, volume 5 , issue 3

doi:10.21926/obm.hg.2103058
Received: August 10, 2020

Accepted: July 01, 2021

Published: July 09, 2021

\begin{abstract}
Anti-TNF $\alpha$ Therapy are used to induce remission and as maintenance therapy in refractory ulcerative colitis (UC) to achieve mucosal healing (MH). However, the time at which mucosal healing should be assessed is unclear. We retrospectively examined the optimal timing for colonoscopy and the criteria to determine the need for the continuation of treatment. We evaluated 44 UC patients that were treated with anti-TNF $\alpha$ Therapy and categorized them into the following groups according to the degree of $\mathrm{MH}$ within 12 months: $\mathrm{MH}$ and non$\mathrm{MH} / \mathrm{NMH}$, early-MH (EMH, healing within three months), and slow $\mathrm{MH} / \mathrm{SMH}$ (healing between 4-12 months). We compared the Mayo Endoscopic Subscore (MES) between the MH vs. $\mathrm{NMH}$ and $\mathrm{SMH}$ vs. NMH groups. The Lichtiger index and blood test results were investigated as predictive factors of $\mathrm{MH}$. $\mathrm{MH}$ was defined as an MES of $\leq 1$. The MES was significantly lower in the $\mathrm{MH}$ group at 3, 6, and 12 months, compared to the $\mathrm{NMH}$ group. Significant changes were observed in the platelet counts, the Lichtiger index, the levels of Creactive protein (lower), and hemoglobin (higher) in the $\mathrm{MH}$ group at 3-and 6-months
\end{abstract}

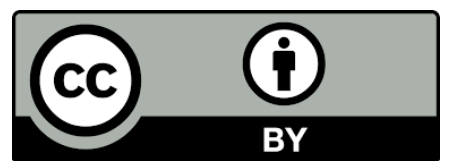

(C) 2021 by the author. This is an open access article distributed under the conditions of the Creative Commons by Attribution License, which permits unrestricted use, distribution, and reproduction in any medium or format, provided the original work is correctly cited. 
following treatment. However, the only significant difference between the $\mathrm{SMH}$ and $\mathrm{NMH}$ groups was in the endoscopic findings at 6 - or 12-months post-treatment. Colonoscopy should be performed three months after treatment with anti-TNF $\alpha$ Therapy. The treatment should be continued in patients who do not achieve mucosal healing at 3-months, and colonoscopy should be repeated at 6- or 12-months to assess the outcomes.

\section{Keywords}

Ulcerative colitis; anti-TNF $\alpha$ therapy; infliximab; adalimumab; timing for colonoscopy

\section{Introduction}

Ulcerative colitis (UC) is the most common intractable disease in Japan, with over 200,000 individuals affected in 2017 [1]. The Japanese National Health Insurance System (as of 2017) covers the use of cytapheresis (CAP), anti-TNFa therapy (infliximab [IFX] and adalimumab [ADA]), and prednisolone (PSL) alternatives such as tacrolimus (TAC) as remission induction therapy for UC [2, 3]. Mucosal healing ( $\mathrm{MH})$ is the goal for induction of remission and is associated with decreased recurrence and bowel resection [4-6]. Anti-TNFa therapy is effective in the treatment of refractory UC for the induction of remission and as maintenance therapy [7-10]. However, the timing of confirmation of $\mathrm{MH}$ by colonoscopy, following anti-TNF $\alpha$ therapy, varies among patients. Thus, there is currently no consensus regarding the exact time of evaluation of $\mathrm{MH}$ by colonoscopy in patients subjected to anti-TNF $\alpha$ therapy.

Clinical evidence indicates that patients with UC can be categorized as those who demonstrate improvements in endoscopic findings within several weeks after anti-TNFa therapy and those who gradually show improvement over several months $[10,11]$. Patients in the latter category may not show any signs of improvement on colonoscopy performed soon after the initiation of treatment. As a result, decision-making regarding the continuation of treatment and the exact time for the evaluation of the therapeutic effects of anti-TNF $\alpha$ therapy remains unclear. Moreover, no studies have examined the optimal timing of colonoscopy in patients who gradually achieve $\mathrm{MH}$. Therefore, it is difficult to decide whether to continue or change treatment. Herein, we performed a retrospective study to determine the optimal timing for a post-anti-TNF $\alpha$ therapy colonoscopy and investigated the criteria to decide on the continuation of treatment in patients with UC.

\section{Patients and Methods}

Data from 44 patients with UC that had been subjected to anti-TNF $\alpha$ therapy (IFX, $n=27 ;$ ADA, $n$ = 17) at our hospital from June 2009 to March 2017 were included in this study. All patients were steroid-resistant or steroid-dependent. The sample included 23 (52.3\%) men and 21 (47.7\%) women, with a median age of 36.5 years (16-78 years). We categorized the 44 patients into two groups based on the patients that had achieved $\mathrm{MH}$ within 12 months after the start of anti-TNFa therapy (MH group, $n=20$ ) and those who did not (non-MH $[N M H]$ group, $n=24)$. The patients that required changes in therapy within the 12 months were classified into the $\mathrm{NMH}$ group.

Colonoscopy was performed at 1, 3, 6, and 12 months after the initiation of treatment to determine the optimal timing. We further categorized the patients in the $\mathrm{MH}$ group as those who 
had achieved mucosal healing within 3-months (early- $\mathrm{MH}[\mathrm{EMH}], \mathrm{n}=11$ ) and those between 4- and 12-months (slow $\mathrm{MH}[\mathrm{SMH}], \mathrm{n}=9$ ). We compared the SMH patients with $\mathrm{NMH}$ ones to determine the predictors of the possibility of continued treatment. Besides, we also examined the predictors of recurrence in $\mathrm{EMH}$.

Outcomes were compared between the groups based on the colonoscopy findings (endoscopic scores), clinical assessments, and the results of the blood tests (Figure 1).

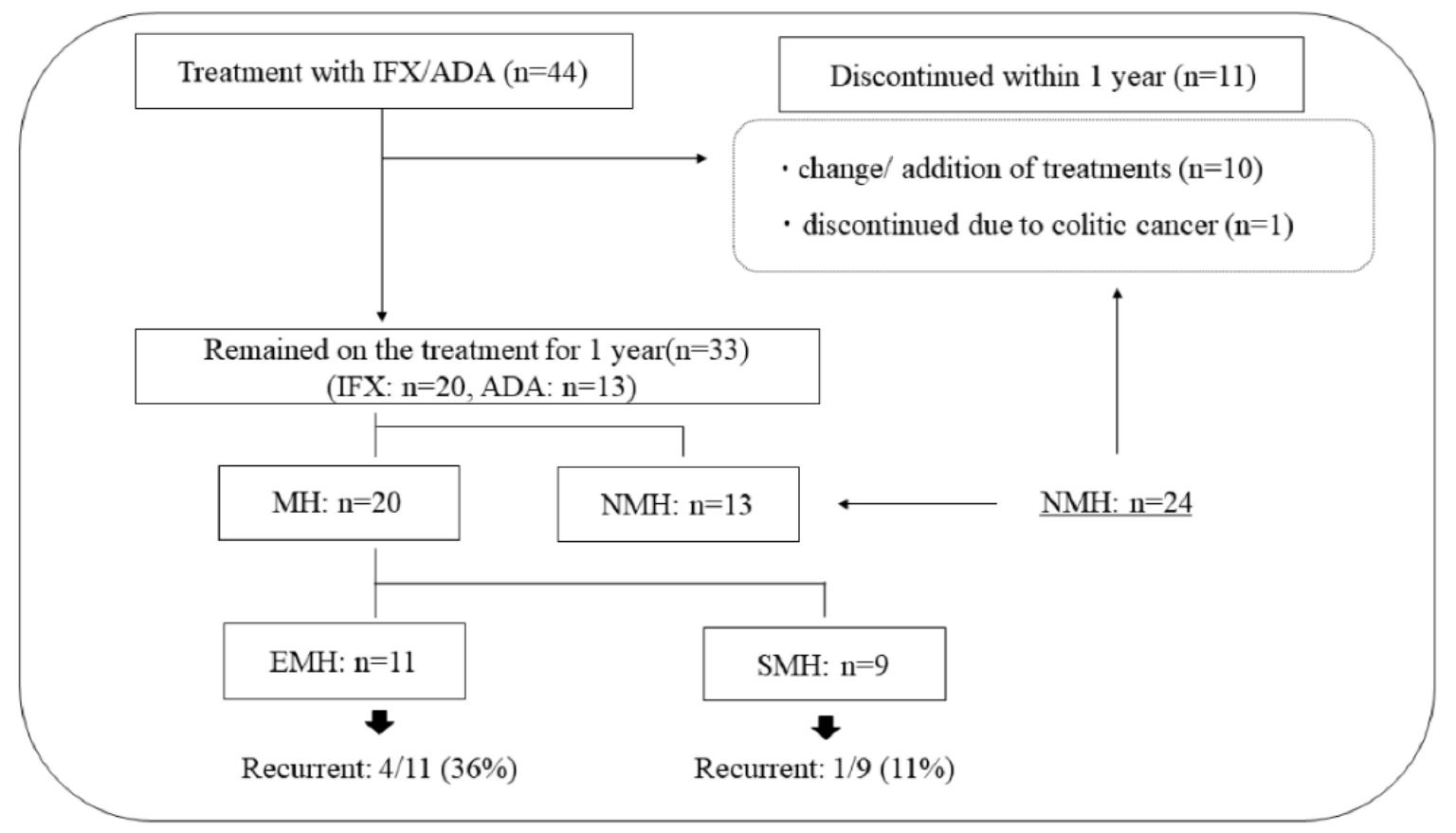

Figure 1 Clinical course of all 44 patients with UC. Patients flow. Forty-four UC patients received anti-TNF $\alpha$ therapy (IFX/ADA). Thirty-three of the 44 patients received antiTNF $\alpha$ therapy for 12 months. MH was achieved in 20 out of 33 patients (EMH: $n=11$, $\mathrm{SMH}: \mathrm{n}=9$ ). IFX, Infliximab; ADA, Adalimumab; $\mathrm{MH}$, mucosal healing; $\mathrm{NMH}$, Nonmucosal healing; EMH, Early-mucosal healing; SMH, Slow-mucosal healing; UC, ulcerative colitis.

In the $\mathrm{MH}$ group, colonoscopy was performed in ten cases after 1 month, in 13 cases after 3 months, in eight cases after 6 months, and in 14 cases after 12 months. In the NMH group, colonoscopy was performed in nine cases after 1 month, five cases after 3 months, 10 cases after 6 months, and nine cases after 12 months. The mean colonoscopy time was $26.7 \pm 14.7$ days (1 month), $87.1 \pm 21.7$ days ( 3 months), $194 \pm 35.3$ days ( 6 months), and $416 \pm 85.3$ days ( 12 months).

We selected the Mayo Endoscopic Subscore (MES) for the evaluation of $\mathrm{MH}$, as it is the gold standard for endoscopic measures [12]. MH was defined as an MES of $\leq 1[13,14]$ and endoscopic recurrence as an MES $\geq 2$ during the follow-up period. Clinical assessments were performed based on the Lichtiger index [15].

We first compared the MES values between the $\mathrm{MH}$ and $\mathrm{NMH}$ groups and then between the SMH and $\mathrm{NMH}$ groups to determine the optimal timing of colonoscopy. The Lichtiger index and the blood parameters such as white blood cell count [WBC] $(/ \mu \mathrm{L})$, hemoglobin $[\mathrm{Hb}](\mathrm{g} / \mathrm{dL})$, platelet count [PIt] $\left(\mathrm{x} 10^{4} / \mu \mathrm{L}\right), \mathrm{C}$-reactive protein [CRP] $(\mathrm{mg} / \mathrm{dL})$, and albumin [Alb] $(\mathrm{g} / \mathrm{dL})$ were also compared between the $\mathrm{MH}$ and $\mathrm{NMH}$ groups, as well as the $\mathrm{SMH}$ and $\mathrm{NMH}$ groups. This was done to establish the 
optimal timing and criteria to determine the need for continuation of treatment with anti-TNF $\alpha$ agents.

\subsection{Statistical Analyses}

The data are presented as the number of cases and median (min-max). The Wilcoxon signed-rank test was used to compare the results between two groups, and a $p$-value of $\leq 0.05$ was considered statistically significant. All the analyses were performed using the statistical program JMP Pro12 (Statistical Discover, SAS, Cary, NC).

\subsection{Ethical Considerations}

The protocol of this study was reviewed and approved by the Ethics Review Committee of Tokyo Women's Medical University (approval number: 5174). Informed consent was obtained from all the patients.

\section{Results}

\subsection{Patient Characteristics and Clinical Course}

The patients' characteristics are summarized in Table 1 . There were 20 patients $(45.5 \%)$ in the $\mathrm{MH}$ group and 24 (54.5\%) in the $\mathrm{NMH}$ group, and their characteristics were not significantly different. Similarly, there were no significant differences between patients in the $\mathrm{SMH}(n=9,20.5 \%)$ and $\mathrm{NMH}$ groups ( $n=24,54.5 \%$ ) (Table 1 and Table 2 ).

Table 1 Characteristics of patients in the $\mathrm{MH}$ and $\mathrm{NMH}$ groups.

\begin{tabular}{llll}
\hline & MH group & NMH group & p-value \\
& $\mathbf{n = 2 0}$ & $\mathbf{n = 2 4}$ & \\
\hline IFX/ADA & $11 / 9$ & $16 / 8$ & 0.4287 \\
Male/female & $11 / 9$ & $12 / 12$ & 0.7409 \\
Age at disease onset, yrs & $28.5(15-75)$ & $20.5(10-61)$ & 0.1006 \\
Age at the time of treatment, yrs & $36.5(23-78)$ & $34.5(16-71)$ & 0.5876 \\
Time since diagnosis, days & $2963(60-9200)$ & $3302(111-14911)$ & 0.8412 \\
Steroid-dependent & $17 / 3$ & $18 / 6$ & 0.4129 \\
/steroid-resistant & & & \\
Disease type & $16 / 4$ & $21 / 3$ & 0.4982 \\
pancolitis/left-sided & $8(40 \%)$ & $12(50 \%)$ & 0.5071 \\
AZA, $\mathrm{n}$ (\%) & & & \\
\hline
\end{tabular}

The data indicate the number of patients (median: min-max). ADA, Adalimumab; AZA, azathioprine; IFX, Infliximab; MH, Mucosal healing; NMH, Non-mucosal healing; yrs, years.

Table 2 Characteristics of patients in the SMH and NMH groups.

\begin{tabular}{llll}
\hline SMH group & NMH group & p-value \\
$n=9$ & $n=24$ & - \\
\hline
\end{tabular}




\begin{tabular}{|c|c|c|c|}
\hline IFX/ADA & $5 / 4$ & $16 / 8$ & 0.5546 \\
\hline Male/female & $4 / 5$ & $12 / 12$ & 0.7761 \\
\hline Age at disease onset, yrs & $29(15-44)$ & $20.5(10-61)$ & 0.2921 \\
\hline $\begin{array}{l}\text { Age at the time of treatment, } \\
\text { yrs }\end{array}$ & $36(23-58)$ & $34.5(16-71)$ & 0.4422 \\
\hline Time since diagnosis, days & $2822(60-9200)$ & 3302 (111-14911) & 0.8241 \\
\hline $\begin{array}{l}\text { Steroid-dependent } \\
\text { /steroid-resistant }\end{array}$ & $8 / 1$ & $18 / 6$ & 0.3847 \\
\hline $\begin{array}{l}\text { Disease type } \\
\text { pancolitis/left-sided }\end{array}$ & $8 / 1$ & $21 / 3$ & 0.9133 \\
\hline$A Z A, n(\%)$ & $3(33 \%)$ & $12(50 \%)$ & 0.3918 \\
\hline
\end{tabular}

In 33 of the 44 patients, treatment with an anti-TNF $\alpha$ agent was continued for 12 months, of which 20 patients were treated with IFX and 13 with ADA. Treatment with IFX was discontinued in one patient on day-109 due to the occurrence of colitic cancer. The treatments were modified in ten patients (addition or an increased dose of PSL, addition of CAP, a change in the anti-TNF $\alpha$ therapy regimen, addition of TAC, or surgery) due to insufficient treatment response or worsening of symptoms. The treatments were modified in six patients within 3-months of initiation (IFX: $n=3$, ADA: $n=3$ ), in two patients between 4- and 6-months (IFX: $n=1, A D A: n=1$ ), and in two patients between 7- and 12-months (IFX: $n=2$ ). Four patients (36\%, IFX: $n=2, A D A: n=2$ ) in the EMH group and one patient $(11 \%$, IFX: $n=1)$ in the SMH group had endoscopic recurrence within 12-months (Figure 1).

\subsection{Findings of Colonoscopy of the UC Patients After Treatment with Anti-TNFa Agents}

\subsubsection{Comparison between the $\mathrm{MH}$ and $\mathrm{NMH}$ Groups}

The MES values of the MH and NMH groups did not vary significantly before treatment and after the completion of 1-month. Subsequently, the MES was significantly lower $(\mathrm{p}<0.05)$ in the MH group compared to the NMH group at 3-months ( $\mathrm{MH}: 1$ [0-3], NMH: 2 [2-3], $\mathrm{p}=0.0219), 6$-months (MH: 1 [0-2], NMH: 2 [2-3], $p=0.0019)$, and 12-months (MH: 1 [0-2], NMH: 2 [2-3], $p=0.0012)$. These findings indicated that colonoscopy should be performed during the third month or later after the initiation of treatment (Table 3, Figures 2A-E).

Table 3 Comparison of the clinical course between the $\mathrm{MH}$ and $\mathrm{NMH}$ groups.

\begin{tabular}{llll}
\hline & $\begin{array}{l}\text { MH group } \\
\mathbf{n}=\mathbf{2 0}\end{array}$ & $\begin{array}{l}\text { NMH group } \\
\mathbf{n = 2 4}\end{array}$ & p-value \\
\hline MES, points: & & & \\
Pre & $3(1-3)$ & $3(2-3)$ & 0.7334 \\
1 mo. post & $2(0-2)$ & $2(2-3)$ & 0.1081 \\
3 mos. post & $1(0-3)$ & $2(2-3)$ & $\underline{0.0219}$ \\
6 mos. post & $1(0-2)$ & $2(2-3)$ & $\underline{0.0019}$
\end{tabular}




\begin{tabular}{|c|c|c|c|}
\hline 12 mos. post & $1(0-2)$ & $2(2-3)$ & $\underline{0.0012}$ \\
\hline \multicolumn{4}{|c|}{ Lichtiger index, points: } \\
\hline Pre & $8(3-15)$ & $7(3-13)$ & 0.3104 \\
\hline 1 mo. post & $4(2-9)$ & $4(2-11)$ & 0.3018 \\
\hline 3 mos. post & $2.5(1-8)$ & $5(2-10)$ & $\underline{0.0016}$ \\
\hline 6 mos. post & $2.5(1-9)$ & $3(2-11)$ & 0.2629 \\
\hline 12 mos. post & $2.5(1-10)$ & $3(1-7)$ & 0.2003 \\
\hline \multicolumn{4}{|l|}{ WBC, $/ \mu \mathrm{L}:$} \\
\hline Pre & $6300(4570-9500)$ & 7160 (3500-11570) & 0.3052 \\
\hline 1 mo. post & 6265 (3630-14150) & $6610(3010-12030)$ & 0.6177 \\
\hline 3 mos. post & $6450(4040-12720)$ & 7390 (3960-13350) & 0.3050 \\
\hline 6 mos. post & $6230(3440-10400)$ & $6550(3880-10190)$ & 0.2934 \\
\hline 12 mos. post & 5070 (4020-9440) & $6130(4020-10220)$ & 0.4014 \\
\hline \multicolumn{4}{|l|}{$\mathrm{Hb}, \mathrm{g} / \mathrm{dL}:$} \\
\hline Pre & $13.0(9.2-15.5)$ & $12.2(8.5-15.1)$ & $\underline{0.0425}$ \\
\hline 1 mo. post & $13.0(9.5-14.9)$ & $12.7(7.9-16.2)$ & 0.3179 \\
\hline 3 mos. post & 13.7 (11.7-15.7) & $12.4(10-16)$ & 0.0719 \\
\hline 6 mos. post & $13.8(11.1-15.4)$ & $12.4(9.9-15.4)$ & $\underline{0.0192}$ \\
\hline 12 mos. post & $13.8(10.6-15.5)$ & $12.7(8.4-15.3)$ & 0.1592 \\
\hline \multicolumn{4}{|l|}{ Plt, $\times 104 / \mu \mathrm{L}:$} \\
\hline Pre & 26.5 (13.3-47.4) & $31.4(19.8-54.2)$ & 0.0518 \\
\hline 1 mo. post & $25.1(13.2-45.9)$ & $28.2(16.8-60.9)$ & 0.0540 \\
\hline 3 mos. post & $22.8(14.7-42)$ & $30.2(16.3-63.3)$ & $\underline{0.0176}$ \\
\hline 6 mos. post & $23.3(11.2-48.4)$ & $32.6(18.1-57.1)$ & $\underline{0.0370}$ \\
\hline 12 mos. post & $22.8(13.3-88.6)$ & $32.9(20.8-69.5)$ & 0.0574 \\
\hline \multicolumn{4}{|l|}{ CRP, mg/dL: } \\
\hline Pre & $0.21(0.03-4.55)$ & $0.45(0.02-7.5)$ & 0.5167 \\
\hline 1 mo. post & $0.09(0-2.77)$ & $0.12(0-10.46)$ & 0.4280 \\
\hline 3 mos. post & $0.05(0-0.33)$ & $0.12(0.02-2.06)$ & $\underline{0.0425}$ \\
\hline 6 mos. post & $0.05(0-1.11)$ & $0.11(0.02-1.55)$ & 0.0707 \\
\hline 12 mos. post & $0.10(0-1.23)$ & $0.2(0-4.87)$ & 0.2771 \\
\hline \multicolumn{4}{|l|}{ Alb, g/dL: } \\
\hline Pre & $4(3.1-4.6)$ & $3.6(3-4.5)$ & 0.1426 \\
\hline 1 mo. post & $4.2(2.8-4.7)$ & $4.1(2.4-4.8)$ & 0.7023 \\
\hline 3 mos. post & $4.4(3.8-4.9)$ & $4.2(3.4-4.7)$ & 0.3927 \\
\hline 6 mos. post & $4.3(3.5-5.2)$ & $4.3(3.6-4.7)$ & 1.0000 \\
\hline 12 mos. post & $4.2(3-4.5)$ & $4.4(3.3-4.8)$ & 0.3714 \\
\hline
\end{tabular}

Alb, albumin; CRP, C-reactive protein; $\mathrm{Hb}$, hemoglobin; MES, Mayo endoscopic sub-score; $\mathrm{MH}$, Mucosal healing; mo, month; NMH, Non-mucosal healing; PIt, Platelets; WBC, White blood cell. 

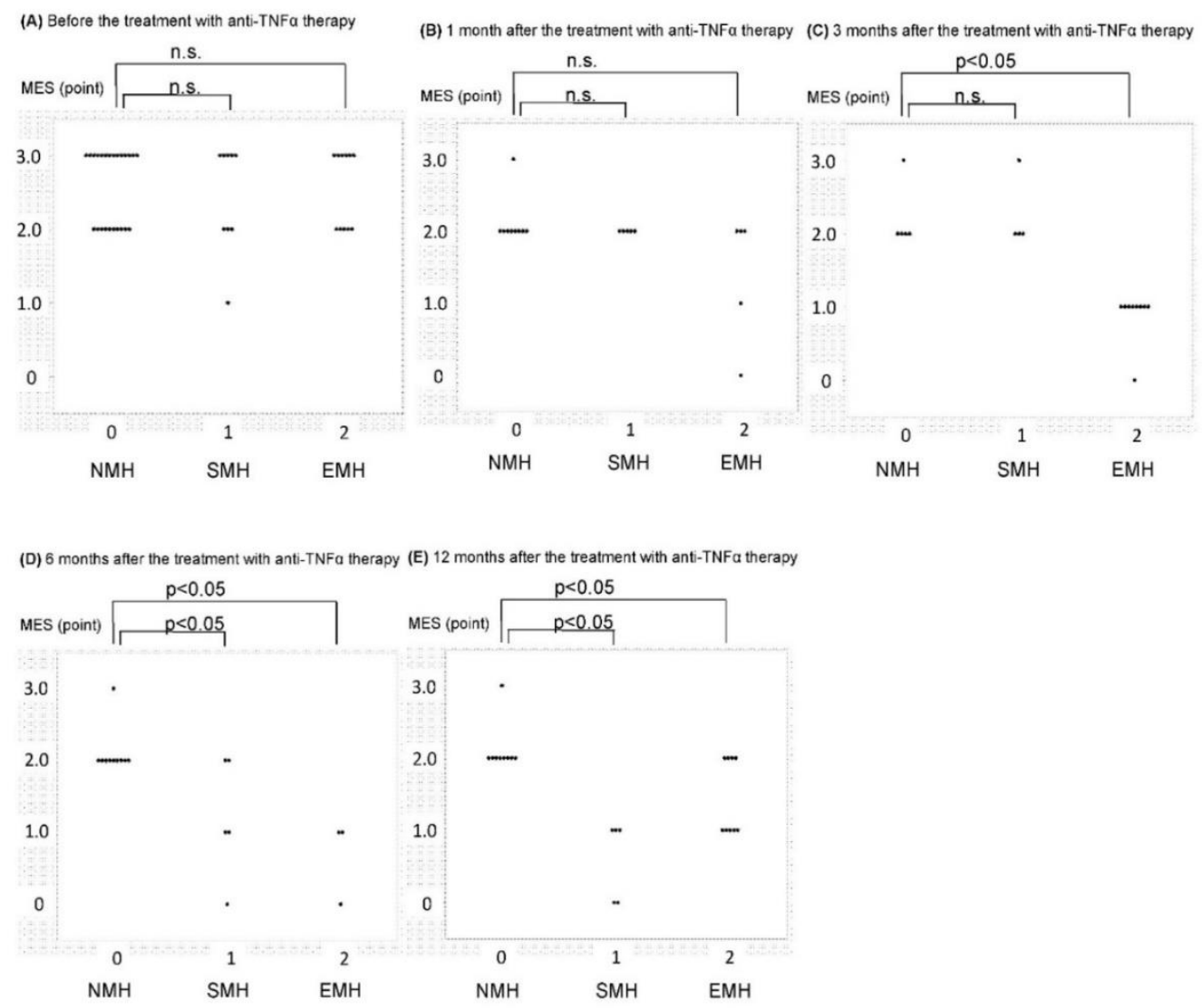

Figure 2 Findings of colonoscopy of the UC patients after treatment with anti-TNF $\alpha$ agents. Comparison between the $\mathrm{NMH}$ and $\mathrm{SMH}$ groups, as well as the $\mathrm{NMH}$ and $\mathrm{MH}$ groups. The MES values were significantly lower $(\mathrm{p}<0.05)$ in the $\mathrm{MH}$ group compared to the NMH group at 3-months. MES, Mayo endoscopic sub-score; UC, ulcerative colitis; $\mathrm{MH}$, mucosal healing; $\mathrm{NMH}$, Non-mucosal healing; EMH, Early-mucosal healing; $\mathrm{SMH}$, Slow-mucosal healing.

\subsubsection{Comparison between the SMH and NMH Groups}

The MES of the SMH and NMH groups did not vary significantly before treatment, at 1-month, and at 3-months after the initiation of treatment with anti-TNF $\alpha$ agents (Table 4, Figures 2A-E). There were significant differences in the MES $(p<0.05)$ between the SMH and NMH groups at 6 months (SMH: 1 [0-2], NMH: 2 [2-3], p = 0.0011) and 12-months (SMH: 1 [0-1], NMH: 2 [2-3], $p=$ 0.0026). These findings indicated that the distinction between $\mathrm{SMH}$ and $\mathrm{NMH}$ should be made by performing a colonoscopy at 6- or 12-months after the initiation of treatment.

Table 4 Comparison of the clinical course between the SMH and NMH groups.

\begin{tabular}{llll}
\hline & $\begin{array}{l}\text { SMH group } \\
\mathbf{n = 9}\end{array}$ & $\begin{array}{l}\text { NMH group } \\
\mathbf{n = 2 4}\end{array}$ & p-value \\
\hline MES, points: & & & \\
Pre & $3(1-3)$ & $3(2-3)$ & 0.7261 \\
1 mo. post & $2(2-2)$ & $2(2-3)$ & 0.5510
\end{tabular}




\begin{tabular}{|c|c|c|c|}
\hline 3 mos. post & $2(2-3)$ & $2(2-3)$ & 1.0000 \\
\hline 6 mos. post & $1(0-2)$ & $2(2-3)$ & $\underline{0.0011}$ \\
\hline 12 mos. post & $1(0-1)$ & $2(2-3)$ & $\underline{0.0026}$ \\
\hline \multicolumn{4}{|c|}{ Lichtiger index, points: } \\
\hline Pre & $10(4-14)$ & $7(3-13)$ & 0.1418 \\
\hline 1 mo. post & $4.5(3-9)$ & $4(2-11)$ & 0.5674 \\
\hline 3 mos. post & $3.5(2-8)$ & $5(2-10)$ & 0.1002 \\
\hline 6 mos. post & $3(2-9)$ & $3(2-11)$ & 0.7217 \\
\hline 12 mos. post & $2.5(1-5)$ & $3(1-7)$ & 0.7468 \\
\hline \multicolumn{4}{|l|}{ WBC, $/ \mu \mathrm{L}:$} \\
\hline Pre & 6635 (5430-9500) & $7160(3500-11570)$ & 0.7010 \\
\hline 1 mo. post & 9570 (3630-14150) & $6610(3010-12030)$ & 0.5025 \\
\hline 3 mos. post & $6370(4040-12720)$ & 7390 (3960-13350) & 0.3016 \\
\hline 6 mos. post & 6735 (3740-10400) & $6550(3880-10190)$ & 0.8429 \\
\hline 12 mos. post & 5895 (4590-8010) & $6130(4020-10220)$ & 1.0000 \\
\hline \multicolumn{4}{|l|}{$\mathrm{Hb}, \mathrm{g} / \mathrm{dL}:$} \\
\hline Pre & $13.6(11.2-15.5)$ & $12.2(8.5-15.1)$ & $\underline{0.0275}$ \\
\hline 1 mo. post & $14.2(9.5-14.9)$ & $12.7(7.9-16.2)$ & 0.2850 \\
\hline 3 mos. post & $13.6(11.7-15)$ & $12.4(10-16)$ & 0.3624 \\
\hline 6 mos. post & $14.1(11.3-14.7)$ & $12.4(9.9-15.4)$ & 0.0836 \\
\hline 12 mos. post & $14.3(11.9-15.5)$ & $12.7(8.4-15.3)$ & 0.1465 \\
\hline \multicolumn{4}{|l|}{ PIt, $\times 104 / \mu \mathrm{L}:$} \\
\hline Pre & $25.7(13.3-40.6)$ & $31.4(19.8-54.2)$ & 0.2175 \\
\hline 1 mo. post & $25.5(13.8-35.7)$ & $28.2(16.8-60.9)$ & 0.4462 \\
\hline 3 mos. post & $24.6(14.9-35.8)$ & $30.2(16.3-63.3)$ & 0.1683 \\
\hline 6 mos. post & $23.9(14.7-31.3)$ & $32.6(18.1-57.1)$ & 0.1335 \\
\hline 12 mos. post & $20.6(17.5-31.5)$ & $32.9(20.8-69.5)$ & 0.1743 \\
\hline \multicolumn{4}{|l|}{ CRP, mg/dL: } \\
\hline Pre & $0.21(0.06-4.55)$ & $0.45(0.02-7.5)$ & 0.5991 \\
\hline 1 mo. post & $0.14(0.03-2.77)$ & $0.12(0-10.46)$ & 0.9833 \\
\hline 3 mos. post & $0.05(0-0.2)$ & $0.12(0.02-2.06)$ & 0.1454 \\
\hline 6 mos. post & $0.06(0-0.2)$ & $0.11(0.02-1.55)$ & 0.1056 \\
\hline 12 mos. post & $0.17(0.01-0.87)$ & $0.2(0-4.87)$ & 0.9278 \\
\hline \multicolumn{4}{|l|}{ Alb, g/dL: } \\
\hline Pre & $4.1(3.6-4.6)$ & $3.6(3-4.5)$ & 0.1312 \\
\hline 1 mo. post & $4.4(2.8-4.7)$ & $4.1(2.4-4.8)$ & 0.5042 \\
\hline 3 mos. post & $4.3(3.8-4.8)$ & $4.2(3.4-4.7)$ & 0.8965 \\
\hline 6 mos. post & $4.3(4.1-4.8)$ & $4.3(3.6-4.7)$ & 0.9130 \\
\hline 12 mos. Post & $4.3(4-4.5)$ & $4.4(3.3-4.8)$ & 0.5154 \\
\hline
\end{tabular}

Alb, albumin; CRP, C-reactive protein; $\mathrm{Hb}$, hemoglobin; MES, Mayo endoscopic sub score; mo, month; NMH, Non mucosal healing; PIt, Platelets; SMH, Slow mucosal healing; WBC, White blood cell. 


\subsubsection{Factors Predicting $\mathrm{MH}$}

The Lichtiger index, platelets, and CRP values at three months were significantly lower in the $\mathrm{MH}$ group compared to the $\mathrm{NMH}$ group $(\mathrm{p}<0.05)$ (Table 3$)$. The platelet counts were significantly lower, and $\mathrm{Hb}$ values were significantly higher in the $\mathrm{MH}$ group at 6 -months post-treatment $(\mathrm{p}<0.05)$. Moreover, the pre-treatment $\mathrm{Hb}$ values were significantly higher in the $\mathrm{MH}$ group $(\mathrm{p}<0.05)$. Similarly, a comparison between the $\mathrm{SMH}$ and $\mathrm{NMH}$ groups revealed that the $\mathrm{Hb}$ values before treatment were significantly higher in the SMH group $(p<0.05)$ (Table 4$)$. There were no significant differences in the Lichtiger index, WBC, $\mathrm{Hb}$, platelets, CRP, or Alb values at 1, 3, 6, and 12 months after the initiation of treatment with anti-TNF $\alpha$ agents. The Lichtiger index improved after 1-month in both the SMH and $\mathrm{NMH}$ groups. Thus, the Lichtiger index alone was not sufficient to predict $\mathrm{MH}$.

\subsubsection{Comparison of the Recurrence and Non-Recurrence Groups in the EMH Group}

A comparison of the four out of 11 patients in the EMH group who had relapsed (recurrence group), with the seven who did not show significant differences in the pre-treatment levels of $\mathrm{Hb}$ and Alb (non-recurrence group), is presented in Table 5. The recurrence group had lower pretreatment $\mathrm{Hb}$ and $\mathrm{Alb}(\mathrm{p}<0.05)$. There was also a significant difference in the levels of $\mathrm{Hb}$ and MES after 12 months of treatment $(p<0.05)$. This suggests that pre-treatment levels of $\mathrm{Hb}$ and Alb may be predictors of relapse in the EMH group.

Table 5 Comparison of the recurrence and non-recurrence groups in the $\mathrm{EMH}$ group.

\begin{tabular}{llll}
\hline & Recurrence group & Non-recurrence group & p-value \\
& $\mathbf{n = 4}$ & $\mathbf{n = 7}$ & \\
\hline MES, points: & $3(2-3)$ & $2(2-3)$ & 0.3827 \\
Pre & $0(0-0)$ & $2(1-2)$ & 0.2357 \\
1 mo. post & $0(0-1)$ & $1(1-1)$ & 0.2386 \\
3 mos. post & - & $1(0-1)$ & - \\
6 mos. post & $2(2-2)$ & $1(1-1)$ & 0.0072 \\
12 mos. Post & & & \\
Lichtiger index, points: & $7(6-15)$ & $8(3-14)$ & 0.9239 \\
Pre & $2(2-6)$ & $2(2-4)$ & 1.0000 \\
1 mo. post & $2(1-4)$ & $2(1-7)$ & 1.0000 \\
3 mos. post & $2(1-5)$ & $2(1-4)$ & 0.6995 \\
6 mos. post & $2(1-4)$ & & 1.0000 \\
12 mos. Post & & $5820(5240-6830)$ & \\
WBC,/ $\mu$ : & $9090(5600-4570)$ & $5230(3770-14150)$ & 0.7055 \\
Pre & $6090(4620-6910)$ & $6340(4110-9900)$ & 0.6366 \\
1 mo. post & $7130(5930-8450)$ & $6170(3440-7480)$ & 0.9247 \\
3 mos. post & $5660(4470-7930)$ & $4570(4020-6410)$ & 0.2703 \\
6 mos. post & $5440(4450-8240)$ & &
\end{tabular}




\begin{tabular}{|c|c|c|c|}
\hline \multicolumn{4}{|l|}{ Hb, g/dL: } \\
\hline Pre & $11(9.2-12.7)$ & $13.7(12-15.5)$ & $\underline{0.0298}$ \\
\hline 1 mo. post & $12.5(10.9-13)$ & $13.1(12.2-14.9)$ & 0.1849 \\
\hline 3 mos. post & 13.4(13.1-14.9) & $14.1(12.5-15.7)$ & 0.4487 \\
\hline 6 mos. post & $12.9(11.1-14.5)$ & $14.2(13.1-15.4)$ & 0.1082 \\
\hline 12 mos. Post & 11.4(10.6-12.1) & $14.1(13.8-15.2)$ & $\underline{0.0195}$ \\
\hline \multicolumn{4}{|l|}{ Plt, $\times 104 / \mu \mathrm{L}:$} \\
\hline Pre & $33.85(20.6-47.4)$ & $27.1(14.2-30.2)$ & 0.5074 \\
\hline 1 mo. post & $23.25(14.8-37.6)$ & $25.0(13.2-27.1)$ & 0.6366 \\
\hline 3 mos. post & $25.95(15.4-36.3)$ & $21.7(14.7-27.4)$ & 0.5083 \\
\hline 6 mos. post & $25.35(11.2-48.4)$ & $22.1(13.3-28.8)$ & 0.8498 \\
\hline 12 mos. Post & 31.05 (13.3-47.6) & $22.8(16-23.3)$ & 0.2683 \\
\hline \multicolumn{4}{|l|}{ CRP, mg/dL: } \\
\hline Pre & $0.905(0.04-1.95)$ & $0.24(0.03-1.02)$ & 0.2151 \\
\hline 1 mo. post & $0.135(0-1.28)$ & $0.06(0-0.25)$ & 0.7048 \\
\hline 3 mos. post & $0.1(0-0.33)$ & $0.05(0-0.17)$ & 0.5681 \\
\hline 6 mos. post & $0.13(0-0.33)$ & $0.05(0.02-1.11)$ & 0.9240 \\
\hline 12 mos. Post & $0.165(0-0.53)$ & $0.04(0.03-0.1)$ & 0.3832 \\
\hline \multicolumn{4}{|l|}{ Alb, g/dL: } \\
\hline Pre & $3.5(3.1-3.6)$ & $4.1(3.6-4.4)$ & $\underline{0.0166}$ \\
\hline 1 mo. post & $4.2(3.7-4.5)$ & $4.05(3.9-4.4)$ & 0.7476 \\
\hline 3 mos. post & $4.4(4.1-4.9)$ & $4.4(3.8-4.6)$ & 1.0000 \\
\hline 6 mos. post & $4.3(3.5-4.7)$ & $4.0(3.8-5.2)$ & 1.0000 \\
\hline 12 mos. Post & $4.0(3.7-4.3)$ & $4.25(4-4.4)$ & 0.3065 \\
\hline
\end{tabular}

Alb, albumin; CRP, C-reactive protein; EMH, Early mucosal healing; Hb, hemoglobin; MES, Mayo endoscopic sub score; mo, month; NMH, Non mucosal healing; PIt, Platelets; WBC, White blood cell.

\section{Discussion}

Anti-TNF $\alpha$ therapy is often used in the treatment of refractory UC, and several studies have demonstrated $\mathrm{MH}$ [16]. However, there is no consensus regarding the timing of performing a colonoscopy to evaluate the effects of treatment in patients with UC. When anti-TNF $\alpha$ therapy was used for the induction of remission, the effects were typically assessed at 8, 30, or 52-54 weeks after the initiation of treatment $[7,9,17-19]$. In the present study, we compared the outcomes between the $\mathrm{MH}$ and $\mathrm{NMH}$ groups, as well as the $\mathrm{SMH}$ and $\mathrm{NMH}$ groups, to determine the optimal timing to perform a colonoscopy to assess the effects of two anti-TNF $\alpha$ therapies (IFX and ADA). We also investigated the criteria to determine the need for continuation of treatment with anti-TNF $\alpha$ therapy. To address these questions, we performed colonoscopy at 1, 3, 6, and 12 months after the completion of treatment in 44 patients with UC. 


\subsection{Colonoscopy Timing for Anti-TNFa Therapy Treated UC Patients}

\subsubsection{Comparison between the $\mathrm{MH}$ and $\mathrm{NMH}$ Groups}

The MES in the MH group was significantly lower at 3, 6, and 12 months after the treatment $(p<0.05)$. These findings suggested that colonoscopy should be performed at 3,6 , or 12 months after treatment to determine the degree of $\mathrm{MH}$ to assess the effects of treatment. Our study also revealed that some patients with $\mathrm{NMH}$ findings at 3-months could achieve $\mathrm{MH}$ after 4-months. UC patients treated with anti-TNF $\alpha$ agents can be classified as those who achieve $\mathrm{MH}$ at an early stage and those who heal gradually.

\subsubsection{Comparison between $\mathrm{SMH}$ and NMH Patients}

To establish the appropriate usage criteria for anti-TNF $\alpha$ therapy, we further categorized the patients into $\mathrm{SMH}$ and $\mathrm{NMH}$ groups and determined the optimal timing to evaluate the effect of treatment in $\mathrm{SMH}$ patients, as well as to distinguish between $\mathrm{SMH}$ and $\mathrm{NMH}$ patients. While the EMH group can be determined to show $\mathrm{MH}$ by colonoscopy at an early stage, the SMH group does not show $\mathrm{MH}$ at the same time; therefore, it is difficult to decide whether to continue or change treatment. By comparing $\mathrm{SMH}$ and $\mathrm{NMH}$, we expect to make appropriate treatment decisions by accurately predicting the difference between the SMH and NMH groups in which anti-TNFa agents work slowly. In the comparison of the biomarkers studied for $\mathrm{SMH}$ and $\mathrm{NMH}$, significant differences in $\mathrm{Hb}$ levels were observed before treatment $(\mathrm{p}<0.05)$. The causes of anemia in UC have been implicated in iron-deficiency anemia that is associated with bleeding from inflamed mucosa, reduced iron absorption, and anemia associated with chronic inflammation (ACD: anemia of chronic disease). We believe that a higher pre-treatment $\mathrm{Hb}$ level may lead to $\mathrm{SMH}$, even if $\mathrm{MH}$ is not achieved early $[20,21]$. As the present results did not examine the etiology of anemia, further studies are required. The MES values in the SMH group were significantly lower at 6 and 12 months $(p<0.05)$. These findings suggested that in SMH patients, colonoscopy should be performed at 6 or 12 months to determine the effect of treatment with anti-TNF $\alpha$ agents.

\subsection{Factors Predicting $\mathrm{MH}$ and Relapsing $\mathrm{EMH}$}

The Lichtiger index, platelets, and CRP values were significantly lower in the $\mathrm{MH}$ group than in the NMH group at 3-months. This suggested that patients with improvements in the Lichtiger index, platelets, and CRP at 3-months were likely to achieve $\mathrm{MH}$ within 12 months and that these may be considered to be predictive factors in UC patients treated with anti-TNF $\alpha$ agents.

Comparison between the $\mathrm{SMH}$ and $\mathrm{NMH}$ groups revealed that while the colonoscopy findings differed, there were no significant differences in the Lichtiger index or hematological parameters (WBC, $\mathrm{Hb}$, platelets, and Alb) at any time point. This indicated that colonoscopy is necessary to evaluate the treatment effects in $\mathrm{SMH}$ and $\mathrm{NMH}$ patients. There was no significant difference in the Lichtiger index between the SMH and NMH groups. In 13 of the $24 \mathrm{NMH}$ patients, although an improvement in the Lichtiger index was observed, the treatment with anti-TNF $\alpha$ agents was continued for 12 months. In contrast, in patients who demonstrated no $\mathrm{MH}$ without improvement in their Lichtiger index, the treatment was discontinued. Our study revealed the possibility that a subset of patients who do not achieve $\mathrm{MH}$ within 3-months might do so within 12-months if 
treatment with anti-TNFa therapy is continued. Thus, colonoscopy should be performed at 6- and 12-months after the initiation of treatment to account for patients who may demonstrate $\mathrm{SMH}$. $\mathrm{MH}$ is an important goal in the treatment of UC apart from clinical remission; therefore, the optimal criteria and timing for the evaluation of $\mathrm{MH}$ should be identified during treatment.

Comparison of the relapse and non-relapse groups in the $\mathrm{EMH}$ group showed significant differences in the levels of $\mathrm{Hb}$ and Alb before treatment and $\mathrm{Hb}$ and MES after 12-months of treatment. This suggests that pre-treatment levels of $\mathrm{Hb}$ and Alb may be predictors of relapse in the EMH group.

This study has some limitations. First, the sample size was not very large $(n=44)$. Moreover, all the patients could not be subjected to multiple endoscopies simultaneously, and the study design was retrospective. A prospective multicenter study is necessary to further explore the issues examined herein.

The strength of our study is that by dividing $\mathrm{MH}$ into $\mathrm{EMH}$ and $\mathrm{SMH}$, we observed that only the Lichtiger index and blood test parameters during treatment could not predict future $\mathrm{MH}$. Furthermore, we also found the involvement of pre-treatment levels of Alb and $\mathrm{Hb}$ as predictors of EMH relapse.

\section{Conclusion}

Colonoscopy performed 3-months after the initiation of treatment with anti-TNF $\alpha$ agents is effective in the assessment of treatment response in patients with UC. Treatment with anti-TNF $\alpha$ agents should be continued in the subset of patients who do not demonstrate $\mathrm{MH}$ at 3-months but possibly heal gradually, based on clinical data and symptoms. Colonoscopy should be repeated at 6- or 12-months in such patients to re-evaluate the treatment response.

\section{Author Contributions}

$\mathrm{HK}, \mathrm{Al}$ and $\mathrm{KT}$ : study concept and design; HK, Al and TO: data acquisition; HK: statistical analysis and drafting of the first version of the manuscript; $\mathrm{HK}, \mathrm{Al}, \mathrm{TO}, \mathrm{SN}$, and $\mathrm{KT}$ : critical revision and approval of the final version of the manuscript.

\section{Competing Interests}

The authors have declared that no competing interests exist.

\section{References}

1. Japan Intractable Diseases Information Center: Japan Intractable Diseases Research Foundation. 2020. Available from: http://www.ibdjapan.org/patient/pdf/01.pdf.

2. Faubion Jr WA, Loftus Jr EV, Harmsen WS, Zinsmeister AR, Sandborn WJ. The natural history of corticosteroid therapy for inflammatory bowel disease: A population-based study. Gastroenterology. 2001; 121: 255-260.

3. Khan N, Abbas A, Williamson A, Balart L. Prevalence of corticosteroids use and disease course after initial steroid exposure in ulcerative colitis. Dig Dis Sci. 2013; 58: 2963-2969.

4. Hanauer SB, Kirsner JB. Treat the patient or treat the disease? Dig Dis. 2012; 30: 400-403.

5. Frøslie KF, Jahnsen J, Moum BA, Vatn MH, IBSEN Group. Mucosal healing in inflammatory bowel 
disease: Results from a Norwegian population-based cohort. Gastroenterology. 2007; 133: 412422.

6. Ardizzone S, Cassinotti A, Duca P, Mazzali C, Penati C, Manes G, et al. Mucosal healing predicts late outcomes after the first course of corticosteroids for newly diagnosed ulcerative colitis. Clin Gastroenterol Hepatol. 2011; 9: 483-489.

7. Rutgeerts $P$, Sandborn WJ, Feagan BG, Reinisch W, Olson A, Johanns J, et al. Infliximab for induction and maintenance therapy for ulcerative colitis. N Engl J Med. 2005; 353: 2462-2476.

8. Armuzzi A, Pugliese D, Danese S, Rizzo G, Felice C, Marzo M, et al. Long-term combination therapy with infliximab plus azathioprine predicts sustained steroid-free clinical benefit in steroid-dependent ulcerative colitis. Inflamm Bowel Dis. 2014; 20: 1368-1374.

9. Sandborn WJ, Van Assche G, Reinisch W, Colombel JF, D'Haens G, Wolf DC, et al. Adalimumab induces and maintains clinical remission in patients with moderate-to-severe ulcerative colitis. Gastroenterology. 2012; 142: 257-265.

10. Colombel JF, Sandborn WJ, Ghosh S, Wolf DC, Panaccione R, Feagan B, et al. Four-year maintenance treatment with adalimumab in patients with moderately to severely active ulcerative colitis: Data from ULTRA 1, 2, and 3. Am J Gastroenterol. 2014; 109: 1771-1780.

11. Suzuki Y, Motoya S, Hanai H, Hibi T, Nakamura S, Lazar A, et al. Four-year maintenance treatment with adalimumab in Japanese patients with moderately to severely active ulcerative colitis. J Gastroenterol. 2017; 52: 1031-1040.

12. Meucci G, Fasoli R, Saibeni S, Valpiani D, Gullotta R, Colombo E, et al. Prognostic significance of endoscopic remission in patients with active ulcerative colitis treated with oral and topical mesalazine: A prospective, multicenter study. Inflamm Bowel Dis. 2012; 18: 1006-1010.

13. Schroeder KW, Tremaine WJ, Ilstrup DM. Coated oral 5-aminosalicylic acid therapy for mildly to moderately active ulcerative colitis. N Engl J Med. 1987; 317: 1625-1629.

14. Colombel JF, Rutgeerts $P$, Reinisch W, Esser D, Wang $Y$, Lang $Y$, et al. Early mucosal healing with infliximab is associated with improved long-term clinical outcomes in ulcerative colitis. Gastroenterology. 2011; 141: 1194-1201.

15. Lichtiger S, Present DH, Kornbluth A, Gelernt I, Bauer J, Galler G, et al. Cyclosporine in severe ulcerative colitis refractory to steroid therapy. N Engl J Med. 1994; 330: 1841-1845.

16. Harbord M, Eliakim R, Bettenworth D, Karmiris K, Katsanos K, Kopylov U, et al. Third European evidence-based consensus on diagnosis and management of ulcerative colitis. Part 2: Current management. J Crohns Colitis. 2017; 11: 769-784.

17. Barreiro M, Lorenzo A, Mera J, Dominguez-Munoz E. W1262 prospective, open pilot study for evaluating the clinical efficacy and mucosal healing rate of infliximab in steroid-dependent ulcerative colitis. Gastroenterology. 2008; 134: A-667.

18. Kobayashi T, Suzuki $\mathrm{Y}$, Motoya $\mathrm{S}$, Hirai F, Ogata $\mathrm{H}$, Ito $\mathrm{H}$, et al. First trough level of infliximab at week 2 predicts future outcomes of induction therapy in ulcerative colitis-results from a multicenter prospective randomized controlled trial and its post hoc analysis. J Gastroenterology. 2016; 51: 241-251.

19. Afif W, Leighton JA, Hanauer SB, Loftus Jr EV, Faubion WA, Pardi DS, et al. Open-label study of adalimumab in patients with ulcerative colitis including those with prior loss of response or intolerance to infliximab. Inflamm Bowel Dis. 2009; 15: 1302-1307.

20. Dignass AU, Gasche C, Bettenworth D, Birgegård G, Danese S, Gisbert JP, et al. European consensus on the diagnosis and management of iron deficiency and anaemia in inflammatory 
bowel diseases. J Crohns Colitis. 2015; 9: 211-222.

21. Weiss G, Gasche C. Pathogenesis and treatment of anemia in inflammatory bowel disease. Haematologica. 2010; 95: 175-178.

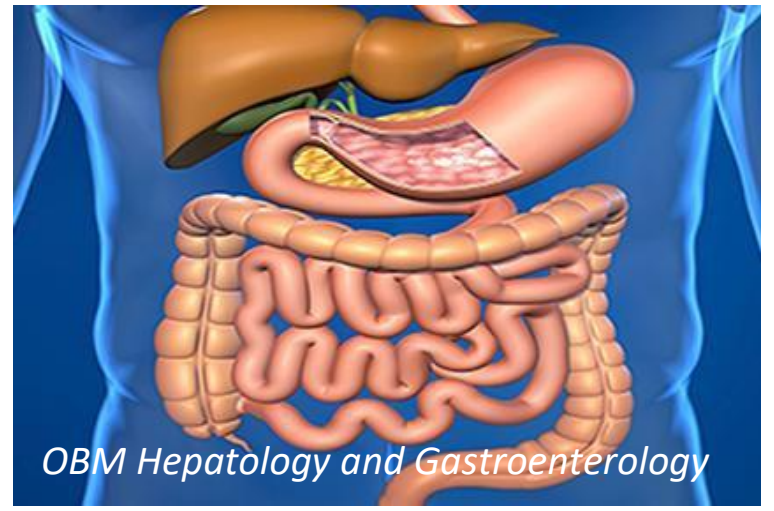

Enjoy OBM Hepatology and Gastroenterology by:

1. Submitting a manuscript

2. Joining in volunteer reviewer bank

3. Joining Editorial Board

4. Guest editing a special issue

For more details, please visit:

http://www.lidsen.com/journals/hg 